\section{JTI}

JOURNAL OF

TRAUMA AND INJURY

\title{
Associated Injuries in Spine Trauma Patients: A Single-Center Experience
}

\author{
Seunghan Yu, M.D.*, Hyuk Jin Choi, M.D.*, Jung Hwan Lee, M.D., \\ Byung Chul Kim, M.D., Mahnjeong Ha, M.D., In Ho Han, M.D., Ph.D. \\ Department of Neurosurgery, Medical Research Institute, Pusan National University \\ Hospital, Busan, Korea
}

Purpose: The purpose of this study was to determine the incidence and characteristics of associated injuries in patients with spine trauma.

Methods: Data of 3,920 consecutive patients admitted to a regional trauma center during a 3-year period were analyzed retrospectively.

Results: Of the 3,920 patients who were admitted to the trauma center during the 3 -year study period, 389 (9.9\%) had major spinal injuries. Among these 389 patients, $303(77.9 \%)$ had associated injuries outside the spine. The most common body region of associated injuries was the extremities or pelvis (194 cases, $49.4 \%$ ), followed by the chest (154 cases, 39.6\%) and face (127 cases, 32.6\%). Of these 303 patients, 149 (64\%) had associated injuries that required surgical treatment such as laparotomy or internal fixation. Associated injuries were more common in patients with lumbar injuries (93.3\%) or multiple spinal injuries (100\%) than in those with lower cervical injuries (67.4\%). There was a significant correlation between the location of the spinal injury and the body region of the associated injury. However, distant associated injuries were also common. Conclusions: Associated injuries were very common in spinal injury patients. Based on demographic groups, the trauma mechanism, and the location of spinal injury, an associated injury should be suspected until proven otherwise. Using a multidisciplinary and integrated approach to treat trauma victims is of the paramount importance.

Keywords: Spinal injuries; Multiple trauma; Trauma centers

\section{INTRODUCTION}

Spinal cord injuries (SCI) have devastating consequences for patients and society. Despite various efforts, the incidence and in-hospital mortality of SCI remain high, and their prevalence is increasing [1]. Considering the anatomical location of the spinal 
column and the nature of the usual injury mechanisms, including traffic accidents and falls, one might expect multiple accompanying injuries. Nevertheless, the literature usually deals with spine trauma in isolation [2]. It is important for spine surgeons to recognize that patients could have injuries in other parts of the body in addition to the spine. Conversely, it is also important for trauma surgeons to understand that injuries concurrent with spinal trauma might not show typical manifestations due to pain or sensory impairment.

The purpose of this study was to determine the incidence and characteristics of associated injuries in patients with spine trauma. The findings could be useful for understanding the nature of spine trauma, and may have implications for providing better care for spine trauma in polytrauma.

\section{METHODS}

\section{Data collection}

Data from 3,920 consecutive patients who were admitted to a regional trauma center of Pusan National University Hospital between January 1, 2017 and December 31, 2019 were reviewed retrospectively. Of these patients, 389 had major spinal injuries. Epidemiological and physiological data were obtained from the Korean Trauma Data Base registry, along with neurological and prognostic data from patients' medical records. This study was approved by the Institutional Review Board (IRB No. H-2011-009096).

\section{Definition and measures}

Major spine injury was defined as a traumatic injury to the spinal column, including fracture, subluxation, dislocation, and neural damage, that required surgical treatment. Minor injuries such as soft tissue injuries and simple fractures were excluded in accordance with the purpose of this study.

Associated injuries were evaluated by the Revised Trauma Score (RTS) for a physiological analysis, along with the Abbreviated Injury Scale and Injury Severity Score (ISS) for an anatomical analysis. In addition to presence of associated injuries, the necessity of common surgical procedures for associated injuries was investigated.

The spinal injury level was analyzed using the Meyer classification [3]. Minor injuries were excluded. Patients with multiple-level spinal injuries were described accordingly. Neurological function was assessed using the American Spinal Injury Association (ASIA) Impairment Scale at the time of injury and at 6 months after the injury.

\section{Statistical method}

Univariate analysis was performed using logistic regression to compare differences according to sex, age group, the mechanism of injury, and initial neurological status. Odds ratios and their 95\% confidence intervals were also calculated for the same purpose. The chi-square and Fisher exact tests were employed to analyze the location of spinal injuries, neurological recovery, and the presence of associated injuries. Correlations between various outcome factors and severity parameters were examined using Spearman rank correlation analysis. All statistical analyses were conducted using $\mathrm{R}$ version 3.6.2 for Windows. $P$-values of less than 0.05 were considered to indicate statistical significance.

\section{RESULTS}

Of 3,920 patients who were admitted to the trauma center during a 3-year period, 389 (9.9\%) had major spinal injuries. Among these 389 patients, 303 (77.9\%) had associated injuries. The most common body region of the associated injuries was the extremities and pelvis (194 cases, 49.4\%), followed by the chest (154 cases, 39.6\%) and face (127 cases, 32.6\%). Of the 303 patients with associated injuries, 149 (64\%) required surgical treatment such as laparotomy or internal fixation. There was no statistically significant difference in the presence of associated injuries according to sex. However, young adults, patients who underwent high-energy falls, and neurologically intact patients showed higher probabilities of having associated injuries (Table 1).

Associated injuries were more common in patients with lumbar injuries (93.3\%) and multiple spinal injuries (100\%) than in those with lower cervical injuries (67.4\%) (Table 2). The location of the spinal injury was correlated 
with the body region of the associated injury (Fig. 1).

Patients with associated injuries had a lower chance of having neurological deficits. However, there was no significant correlation between the presence of an associated injury and neurological recovery (Table 3 ).

We evaluated outcome variables including length of stay (LOS), LOS in the intensive care unit (ICU LOS), duration of mechanical ventilation, total amount of packed

Table 1. Associated injuries according to injury characteristics

\begin{tabular}{|c|c|c|c|c|c|}
\hline & $\begin{array}{l}\text { Number of patients } \\
\text { with major spinal injury }\end{array}$ & $\begin{array}{l}\text { Number of patients } \\
\text { with associated injury }\end{array}$ & OR & $95 \% \mathrm{Cl}$ & $p$-value \\
\hline \multicolumn{6}{|l|}{ Sex } \\
\hline Male & $288(74.0)$ & $224(26.1)$ & Reference & & \\
\hline Female & $101(26.0)$ & $79(73.9)$ & 1.026 & $2.651-4.621$ & 0.927 \\
\hline \multicolumn{6}{|l|}{ Age group } \\
\hline Young adult (<40) & $80(20.6)$ & $72(23.8)$ & Reference & & \\
\hline Middle age (40-65) & $217(55.8)$ & $163(53.8)$ & 0.335 & $0.152-0.741$ & $0.007^{a}$ \\
\hline Old age $(>65)$ & $92(23.7)$ & $68(22.4)$ & 0.315 & $0.132-0.748$ & $0.009^{a}$ \\
\hline \multicolumn{6}{|l|}{ Etiology of injury } \\
\hline Car accident & $82(21.1)$ & $60(19.8)$ & Reference & & \\
\hline Motorcycle/bicycle & $59(15.2)$ & $51(16.8)$ & 2.338 & $0.959-5.699$ & 0.062 \\
\hline High energy fall & $178(45.8)$ & $150(49.5)$ & 1.964 & $1.042-3.701$ & $0.037^{a}$ \\
\hline Trivial fall & $24(6.2)$ & $11(3.6)$ & 0.310 & $0.121-0.794$ & $0.015^{\mathrm{a}}$ \\
\hline Etc. & $46(11.8)$ & $31(10.2)$ & 0.758 & $0.345-1.664$ & 0.489 \\
\hline \multicolumn{6}{|l|}{ Initial neurologic status } \\
\hline Complete injury & $56(14.4)$ & $43(14.2)$ & Reference & & \\
\hline Incomplete injury & $261(67.1)$ & $195(64.4)$ & 0.893 & $0.452-1.764$ & 0.745 \\
\hline Intact & $72(18.5)$ & $65(21.5)$ & 2.807 & $1.037-7.603$ & $0.042^{\mathrm{a}}$ \\
\hline
\end{tabular}

Values are presented as number (\%).

OR: odds ratio, Cl: confidential interval.

aStatistically significant differences ( $p$-value $<0.05$ ).

Table 2. Associated injuries according to the location of the spinal injury

\begin{tabular}{|lccccccc|}
\hline & $\begin{array}{c}\text { Upper cervical } \\
\text { (C1-2) }\end{array}$ & $\begin{array}{c}\text { Lower cervical } \\
\text { (C3-7) }\end{array}$ & $\begin{array}{c}\text { Thoracic } \\
\text { (T1-10) }\end{array}$ & $\begin{array}{c}\text { Thoracolum- } \\
\text { bar (T11-L2) }\end{array}$ & Lumbar (L3-5) & Multiple & p-value \\
\hline $\begin{array}{l}\text { Number of patients with } \\
\text { major spinal injury }\end{array}$ & 23 & 187 & 27 & 106 & 30 & 16 & \\
Associated injury & $20(87)$ & $126(67.4)$ & $24(88.9)$ & $89(84)$ & $28(93)$ & $16(100)$ & $<0.001^{\mathrm{a}}$ \\
Head/neck & $52.2 \%$ & $27.8 \%$ & $44.4 \%$ & $21.7 \%$ & $16.7 \%$ & $37.5 \%$ & $0.01^{\mathrm{a}}$ \\
Face & $52.2 \%$ & $35.8 \%$ & $22.2 \%$ & $23.6 \%$ & $43.3 \%$ & $25.0 \%$ & $0.03^{\mathrm{a}}$ \\
Chest & $52.2 \%$ & $24.6 \%$ & $70.4 \%$ & $48.1 \%$ & $43.3 \%$ & $81.3 \%$ & $<0.001^{\mathrm{a}}$ \\
Abdomen & $26.1 \%$ & $7.0 \%$ & $25.9 \%$ & $29.2 \%$ & $23.3 \%$ & $18.8 \%$ & $<0.001^{\mathrm{a}}$ \\
\hline Pelvis/extremity & $69.6 \%$ & $30.5 \%$ & $66.7 \%$ & $63.2 \%$ & $80.0 \%$ & $75.0 \%$ & $<0.001^{\mathrm{a}}$ \\
\hline
\end{tabular}

Values are presented as number (\%).

astatistically significant differences ( $p$-value<0.05). 
cell transfusion, and Glasgow Outcome Scale (GOS) at 6 months after the injury. Both the ISS and RTS were closely correlated with most variables (Table 4 ). The ISS calculated without the spinal injury ( ISS $_{\text {extraspinal }}$ ) showed correlations with LOS and total amount of packed cell transfusion.

\section{DISCUSSION}

In this study, $77.9 \%$ of patients with major spinal injuries had associated injuries. In previous studies, the prevalence of associated injuries has been reported to be
$28.8-54.4 \%$ [2-5]. The large difference in the prevalence between the present study and previous studies might be due to the following factors: 1) in our study, only patients with major spinal injuries were included;2) since Pusan National University Hospital is a regional trauma center, more severely injured patients could be selected; and 3) at our facility, computed tomography scans of the chest and abdomen are included in the routine protocol, making it possible to diagnose more associated injuries. A large portion of associated injuries (64\%) needed surgical treatment, which required surgeons specializing in the corresponding body region. This finding underscores the need for a multidisciplinary approach to properly manage

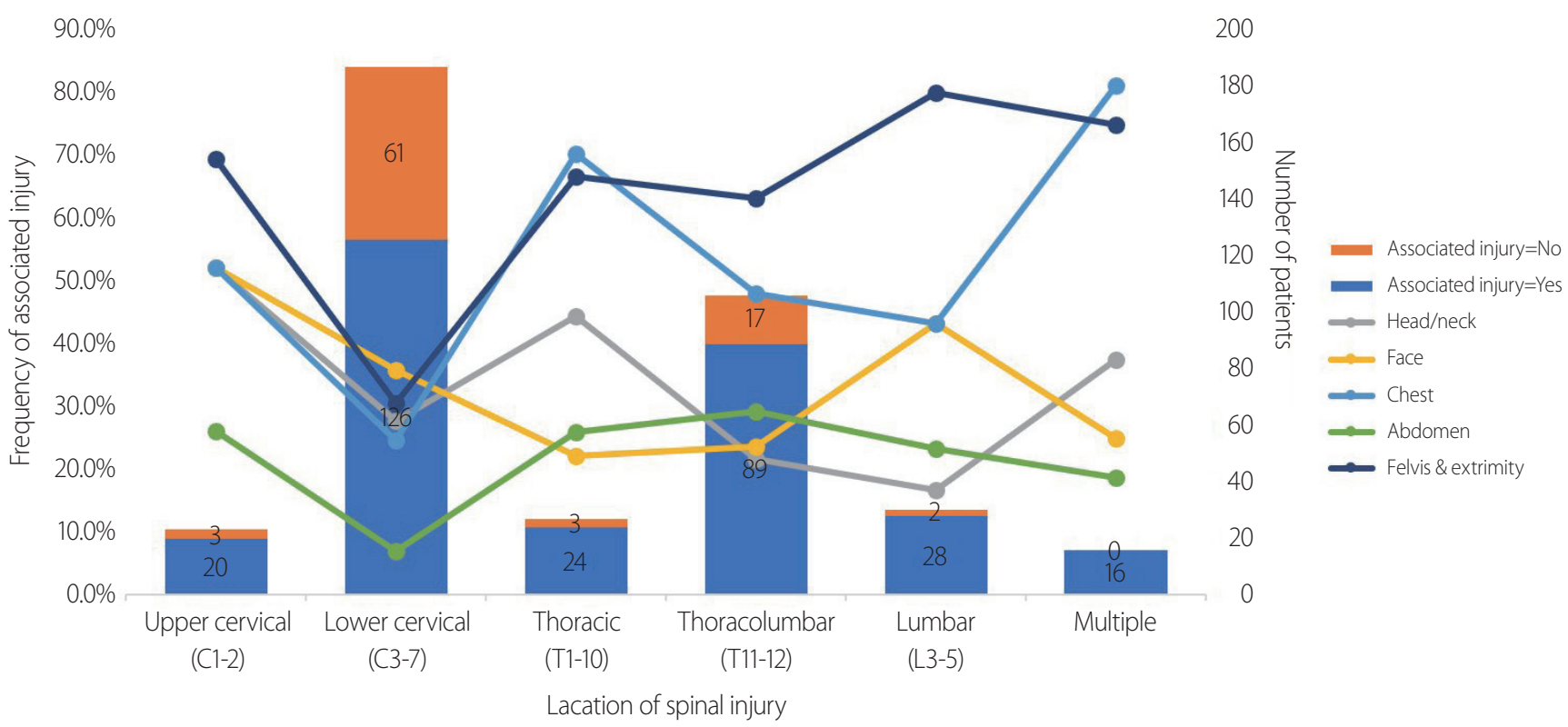

Fig. 1. Correlations between the location of the spinal injury and the body region of the associated injury.

Table 3. Correlation between neurological status and the presence of an associated injury

\begin{tabular}{|lccc|}
\hline & Associated injury (=YES) & Associated injury (=NO) & p-value \\
\hline Number of patients & 303 & 86 & $73(21.8)$ \\
\hline Patients with initial neurologic deficit & $238(78.5)$ & $18(22.8)$ & 0.224 \\
Recovery $^{\text {a }}$ & $52(21.8)$ & $4(5.1)$ & 0.632 \\
Full recovery $^{\text {b }}$ & $10(4.2)$ & 0.746 \\
\hline
\end{tabular}

Values are presented as number (\%).

ASIA: American Spinal Injury Association.

${ }^{a}$ Any positive change in ASIA impairment scale at 6-month after the injury.

${ }^{b}$ Recovery to ASIA impairment scale $E$ at 6-month after the injury. 
trauma patients, in addition to making a precise diagnosis.

In our study, high-energy falls were the most common cause of injury, followed by car accidents and motorcycle accidents, consistent with previous epidemiological studies [5-8]; this finding can be explained by the high-energy nature of these mechanisms. These causes of injury are also the most commonly associated with injuries outside the spine. Thus, special attention to the presence of associated injuries is needed when treating trauma patients with high-energy injury mechanisms.

Of the 389 patients who had major spinal injuries, 72 $(18.5 \%)$ were initially neurologically intact; however, these patients were disproportionately likely to have associated injuries (Table 1). Saboe et al. [2] reported similar results. We hypothesize that in this group, damage is distributed to other systems of the body instead of being focused on the spinal column; thus, these patients are less likely to have cord injuries. However, further study is needed to support this hypothesis.

The most common site of spinal injuries was the lower cervical region (C3-7, 48.1\%) and thoracolumbar junction (T11-L2, 27.2\%). However, associated injuries were more prevalent in patients with injuries at the thoraco- lumbar junction (84\%) than in those with injuries in the lower cervical region (67.4\%). We suspect that injuries to the biomechanically more stable thoracolumbar area might reflect higher-energy mechanisms, increasing the likelihood of associated injuries. All cases with multiple locations of spinal injuries had associated injuries. Thus, physicians should pay special attention to associated injuries when encountering patients with spinal injuries in more than one location. We also identified a significant correlation between the location of the spinal injury and the body region of the associated injury. The anatomical vicinity between spinal injuries and associated injuries has been studied before, especially for lumbar spine fractures and abdominal injuries [9-11]. However, in our study, abdominal injuries were more frequent in patients with upper cervical injuries (26.1\%) than in those with lumbar injuries (23.3\%). Moreover, facial injuries were more common among patients with lumbar injuries (43.3\%) than in those with lower cervical injuries (35.8\%). Therefore, non-contiguous or remote injuries should also be suspected.

The ISS [12,13] and RTS [14] have been used widely to evaluate the severity of trauma victims. In our study, both parameters were closely correlated with various outcome

Table 4. Correlations between various outcome variables and injury severity parameters

\begin{tabular}{|c|c|c|c|c|c|}
\hline & LOS & ICULOS & Ventilator time & Transfusion $^{c}$ & GOS \\
\hline \multicolumn{6}{|l|}{ ISS } \\
\hline$N$ & 389 & 389 & 389 & 389 & 389 \\
\hline$r$ & 0.399 & 0.385 & 0.389 & 0.471 & -0.229 \\
\hline$p$-value & $<0.001^{\mathrm{a}}$ & $<0.002^{\mathrm{a}}$ & $<0.003^{\mathrm{a}}$ & $<0.004^{a}$ & $<0.005^{\mathrm{a}}$ \\
\hline \multicolumn{6}{|c|}{ ISS extraspinal $^{b}$} \\
\hline$N$ & 389 & 389 & 389 & 389 & 389 \\
\hline$r$ & 0.262 & 0.165 & 0.165 & 0.53 & 0.082 \\
\hline$p$-value & $<0.001^{\mathrm{a}}$ & $0.001^{\mathrm{a}}$ & $0.001^{\mathrm{a}}$ & $<0.001^{\mathrm{a}}$ & 0.106 \\
\hline \multicolumn{6}{|l|}{ RTS } \\
\hline N & 389 & 389 & 389 & 389 & 389 \\
\hline$r$ & -0.33 & -0.362 & -0.423 & -0.604 & 0.147 \\
\hline$p$-value & $<0.001^{a}$ & $<0.002^{\mathrm{a}}$ & $<0.003^{\mathrm{a}}$ & $<0.004^{a}$ & $0.004^{\circ}$ \\
\hline
\end{tabular}

LOS: length of stay, GOS: Glasgow Outcome Scale, ISS: injury severity score, RTS: revised trauma scale.

aStatistically significant differences ( $p$-value<0.05).

bISS score calculated without spinal injury.

'Total amount of packed red blood cell transfusion. 


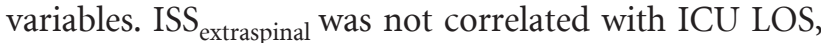
the duration of mechanical ventilation, or GOS. Thus, the spinal injury itself might affect the abovementioned variables more strongly than an associated injury.

This study has some limitations. First, our study was a retrospective single-center study with limited number of patients. Further randomized prospective studies with larger sample sizes are needed to establish more accurate prediction models for spinal injury patients. Nevertheless, these findings show the importance of an integrated approach to treat trauma patients.

\section{CONCLUSION}

Spinal injuries are quite common in multiple trauma patients. Conversely, associated injuries are very common in spinal injury patients. In particular, associated injuries should be suspected in young adults, patients with high-energy trauma, and neurologically intact patients. Clinicians should initially consider the possibility of an associated injury in the same general body region as the spinal injury, but remote injuries should be screened as well. Above all, a multidisciplinary, integrated approach to multiple trauma victims is of the paramount importance.

\section{REFERENCES}

1. Jain NB, Ayers GD, Peterson EN, Harris MB, Morse L, O'Connor KC, et al. Traumatic spinal cord injury in the United States, 1993-2012. JAMA 2015;313:2236-43.

2. Saboe LA, Reid DC, Davis LA, Warren SA, Grace MG. Spine trauma and associated injuries. J Trauma 1991;31:43-8.

3. Meyer PR. Surgery of spine trauma. New York:Churchill Living- stone; 1989.

4. Chu D, Lee YH, Lin CH, Chou P, Yang NP. Prevalence of associated injuries of spinal trauma and their effect on medical utilization among hospitalized adult subjects--a nationwide data-based study. BMC Health Serv Res 2009;9:137.

5. Leucht P, Fischer K, Muhr G, Mueller EJ. Epidemiology of traumatic spine fractures. Injury 2009;40:166-72.

6. Liu P, Yao Y, Liu MY, Fan WL, Chao R, Wang ZG, et al. Spinal trauma in mainland China from 2001 to 2007: an epidemiological study based on a nationwide database. Spine (Phila Pa 1976) 2012;37:1310-5

7. Wang CM, Chen Y, DeVivo MJ, Huang CT. Epidemiology of extraspinal fractures associated with acute spinal cord injury. Spinal Cord 2001;39:589-94.

8. Wang H, Zhang Y, Xiang Q, Wang X, Li C, Xiong H, et al. Epidemiology of traumatic spinal fractures: experience from medical university-affiliated hospitals in Chongqing, China, 2001-2010. J Neurosurg Spine 2012;17:459-68.

9. Dai LY, Yao WF, Cui YM, Zhou Q. Thoracolumbar fractures in patients with multiple injuries: diagnosis and treatment-a review of 147 cases. J Trauma 2004;56:348-55.

10. Hsu JM, Joseph T, Ellis AM. Thoracolumbar fracture in blunt trauma patients: guidelines for diagnosis and imaging. Injury 2003;34:426-33.

11. Rabinovici R, Ovadia P, Mathiak G, Abdullah F. Abdominal injuries associated with lumbar spine fractures in blunt trauma. Injury 1999;30:471-4.

12. Loftis KL, Price J, Gillich PJ. Evolution of the abbreviated injury scale: 1990-2015. Traffic Inj Prev 2018;19(Suppl 2):S109-13.

13. Park Y, Chung M, Lee GJ, Lee MA, Park JJ, Choi KK, et al. Characteristics of Korean trauma patients: a single-center analysis using the Korea trauma database. J Trauma Inj 2016;29:155-60.

14. Champion HR, Sacco WJ, Copes WS, Gann DS, Gennarelli TA, Flanagan ME. A revision of the trauma score. J Trauma 1989;29:623-9. 